\section{(6) OPEN ACCESS}

\title{
Modification of structural lesions on MRI of the sacroiliac joints by etanercept in the EMBARK trial: a 12-week randomised placebo-controlled trial in patients with non-radiographic axial spondyloarthritis
}

Walter P Maksymowych, ${ }^{1}$ Stephanie Wichuk, ${ }^{1}$ Maxime Dougados, ${ }^{2}$ Heather E Jones, ${ }^{3}$ Ron Pedersen, ${ }^{4}$ Annette Szumski, ${ }^{5}$ Lisa Marshall, ${ }^{3}$ Jack F Bukowski, ${ }^{6}$ Robert G Lambert ${ }^{7}$

\begin{abstract}
Handling editor Tore K Kvien
- Additional material is published online only. To view please visit the journal online (http://dx.doi.org/10.1136/ annrheumdis-2017-211605).

${ }^{1}$ Department of Medicine, University of Alberta, Edmonton, Alberta, Canada

${ }^{2}$ Paris Descartes University, Rheumatology Department, Cochin Hospital, Assistance Publique-Hôpitaux de Paris, INSERM (U1153): Clinical Epidemiology and Biostatistics, PRES Sorbonne Paris-Cité France

${ }^{3}$ Medical Affairs, Pfizer, Collegeville, Pennsylvania, USA ${ }^{4}$ Department of Biostatistics, Pfizer, Collegeville, Pennsylvania, USA

${ }^{5}$ Biostatistics, inVentiv Health, Princeton, New Jersey, USA ${ }^{6}$ Clinical Affairs, Pfizer,

Collegeville, Pennsylvania, USA ${ }^{7}$ Department of Radiology and Diagnostic Imaging, University of Alberta, Edmonton, Alberta, Canada
\end{abstract}

Correspondence to Dr Walter P Maksymowych, Department of Medicine University of Alberta, Edmonton, Alberta T6G 2S2, Canada; walter.maksymowych@ualberta. ca

Received 5 April 2017 Revised 8 August 2017 Accepted 8 September 2017 Published Online First 29 September 2017

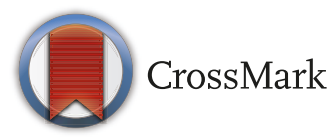

To cite: Maksymowych WP, Wichuk S, Dougados M, et al. Ann Rheum Dis 2018;77:78-84

\section{ABSTRACT}

Objective To evaluate the impact on structural lesions observed on MRI in the sacroiliac joints (SIJ) at 12 weeks in patients with non-radiographic axial spondyloarthritis (nr-axSpA) receiving etanercept or placebo in EMBARK (Effect of Etanercept on Symptoms and Objective Inflammation in nr-axSpA, a 104 week study).

Methods Patients were randomised to double-blind etanercept $50 \mathrm{mg} /$ week or placebo for 12 weeks.

Structural lesions at baseline and 12 weeks were scored by two independent readers using the Spondyloarthritis Research Consortium of Canada (SPARCC) SIJ structural score (SSS) on T1-weighted MRI. Change in SPARCC SSS and correlation with improvement in clinical outcomes was evaluated.

Results MRI scans from 185 patients (etanercept, $n=88$; placebo, $n=97$ ) were reviewed. At baseline, there were no significant differences in mean SPARCC SSS between etanercept and placebo. From baseline to 12 weeks, change in mean SPARCC SSS was significantly greater for etanercept than placebo for erosion $(-0.57$ vs -0.08 , respectively, adjusted $p$ value $=0.017$ ) and backfill ( 0.36 vs 0.06 , adjusted $p$ value $=0.022$ ). A treatment difference was also present for the subgroup of patients with SIJ inflammation on MRI (SPARCC bone marrow oedema $\geq 2$ ): erosion: -0.81 versus -0.13 for etanercept versus placebo, respectively, $p=0.007$; backfill: 0.48 versus 0.08 , respectively, $p=0.032$. Decrease in erosion and increase in backfill correlated with improvement in more clinical outcomes for etanercept than placebo.

Conclusion Treatment with etanercept was associated with significantly greater reduction in erosions and increase in backfill at 12 weeks compared with placebo, consistent with a very early reparative response to antitumour necrosis factor therapy. The impact on disease progression in spondyloarthritis should be studied further.

Trial registration number NCT01258738; Postresults.

\section{INTRODUCTION}

Sacroiliitis in axial spondyloarthritis (axSpA) is typically detected on pelvic radiography and is considered a defining feature of this disease. ${ }^{1}$ It reflects structural changes resulting from inflammation and ranges from erosion in early disease to sclerosis and ankylosis in later stages. However, it has not been used as an outcome for studies of disease-modifying therapy because it is not reliably detected, definite features may not be observed for several years after symptom onset, and its lack of sensitivity to change requires that studies be conducted over several years.

MRI of the sacroiliac joint (SIJ) is a major advance because it detects inflammation soon after disease onset and may depict structural lesions, even in patients with non-radiographic axSpA (nr-axSpA). ${ }^{1-5}$ MRI evaluation of the SIJ combines information visualised simultaneously on two types of routine MRI scans. The T1-weighted (T1W) sequence detects signal from fat, so adult bone marrow of iliac and sacral bones is bright due to its fat content. ${ }^{6}$ The signal from fat can be suppressed, allowing visualisation of inflammation in the bone marrow using fat-suppressed sequences, such as short tau inversion recovery (STIR), which is a water-sensitive sequence. Cortical bone is dark on both sequences.

Several structural lesions may be observed on T1W MRI of the SIJ. ${ }^{7}$ A breach in cortical bone of iliac or sacral bones and loss of bright signal from adjacent marrow matrix indicates erosion. ${ }^{67}$ STIR scans show increased signal if inflammation is still active. When inflammation in bone marrow resolves, it may be replaced by new tissue, fat metaplasia, appearing bright on T1W MRI. Inflammation in an erosion may be replaced by new tissue, termed backfill. Ankylosis is apparent on T1W MRI when marrow matrix traverses the joint space and the dark signal from cortical bone is lost. ${ }^{67}$ Standardised definitions for these lesions have been developed and validated together with a scoring method that assesses individual lesions. ${ }^{7}$

Modification of structural lesions by antitumour necrosis factor (anti-TNF) therapy has not been demonstrated in a randomised controlled trial (RCT) in SpA using radiography of the spine because it is insufficiently sensitive to change within the time frame of such trials. Structural lesions in the SIJ are likely to predate development of spinal disease. $^{3}$ In a small placebo-controlled trial of patients with axSpA, most of whom met the modified New York (mNY) criteria for radiographic damage, differences from baseline were observed in bone marrow oedema (BME) and structural lesions on MRI following 12 weeks of adalimumab therapy. ${ }^{8}$ However, no differences were observed 


\begin{tabular}{|c|c|c|c|c|}
\hline \multirow[b]{2}{*}{ Characteristics } & \multicolumn{2}{|c|}{$\begin{array}{l}\text { Patients with MRI } \\
\text { scans }(n=185)\end{array}$} & \multicolumn{2}{|c|}{$\begin{array}{l}\text { Full mITT } \\
\text { population }(n=215)\end{array}$} \\
\hline & ETN, $n=88$ & PBO, n=97 & ETN, $n=106$ & PBO, $n=109$ \\
\hline Age, years & $31.7(7.8)$ & $32.2(7.9)$ & $31.9(7.8)$ & $32.0(7.8)$ \\
\hline Male, n (\%) & $58(65.9)$ & $54(55.7)$ & $68(64.2)$ & $62(56.9)$ \\
\hline White, n (\%) & $68(77.3)$ & $71(73.2)$ & $79(74.5)$ & $79(72.5)$ \\
\hline $\begin{array}{l}\text { Symptom duration, } \\
\text { years }\end{array}$ & $2.5(2.0)$ & $2.4(1.5)$ & $2.4(1.9)$ & $2.5(1.8)$ \\
\hline $\begin{array}{l}\text { Concomitant DMARD } \\
\text { use, } \mathrm{n}(\%)\end{array}$ & $19(21.6)$ & $20(20.6)$ & $21(19.8)$ & $21(19.3)$ \\
\hline $\begin{array}{l}\text { Family history of SpA, } \\
n(\%)\end{array}$ & $26(29.6)$ & $21(21.7)$ & $28(26.4)$ & $23(21.1)$ \\
\hline ASDAS-CRP & $3.0(0.9)$ & $2.9(1.0)$ & $3.0(0.9)$ & $3.0(1.0)$ \\
\hline BASDAI (0-10) & $5.9(1.8)$ & $6.0(1.9)$ & $6.0(1.8)$ & $6.0(1.9)$ \\
\hline $\begin{array}{l}\text { Total back pain } \\
(0-10 \mathrm{~cm} \text { VAS) }\end{array}$ & $5.5(2.5)$ & $5.4(2.3)$ & $5.5(2.4)$ & $5.5(2.4)$ \\
\hline BASFI (0-10 cm VAS) & $4.2(2.5)$ & $3.8(2.5)$ & $4.2(2.5)$ & $3.9(2.5)$ \\
\hline CRP, mg/L & $7.4(11.2)$ & $6.3(10.7)$ & $6.8(10.6)$ & $6.4(10.5)$ \\
\hline CRP $>3$ mg/L, n (\%) & $44(50.0)$ & $39(40.2)$ & $48(45.3)$ & $44(40.4)$ \\
\hline $\begin{array}{l}\text { HLA-B27 positive, } \\
\text { n (\%) }\end{array}$ & $60(68.2)$ & $73(75.3)$ & $72(67.9)$ & $83(76.2)$ \\
\hline $\begin{array}{l}\text { MRI sacroiliitis } \\
\text { positive }^{*}, \mathrm{n}(\%)\end{array}$ & $74(84.1)$ & $78(80.4)$ & $87(82.1)$ & $87(79.8)$ \\
\hline $\begin{array}{l}\text { MRI sacroiliitis } \\
\text { positive* or } \\
\text { CRP>3 mg/dL, n (\%) }\end{array}$ & $80(90.9)$ & 85 (87.6) & $94(88.7)$ & $95(87.2)$ \\
\hline $\begin{array}{l}\text { SPARCC MRI SIJ score } \\
(0-72)\end{array}$ & $8.3(10.1)$ & $7.7(10.1)$ & $8.0(9.7)$ & $7.7(10.1)$ \\
\hline $\begin{array}{l}\text { SPARCC MRI spine 23- } \\
\text { DVU score (0-414) }\end{array}$ & $5.5(9.7)$ & $3.9(7.2)$ & $5.2(9.3)$ & $3.8(7.0)$ \\
\hline \multicolumn{5}{|c|}{$\begin{array}{l}\text { All values are mean (SD) unless otherwise noted. } \\
\text { *Baseline MRIs were read by a central imaging reader for the presence of } \\
\text { sacroiliitis according to ASAS definition. }{ }^{2} \\
\text { ASAS, Assessment of SpondyloArthritis International Society; ASDAS, Ankylosing } \\
\text { Spondylitis Disease Activity Score; BASFI, Bath Ankylosing Spondylitis Functional } \\
\text { Index; CRP, C-reactive protein; DMARD, disease-modifying antirheumatic drug; DVU, } \\
\text { discovertebral unit; ETN, etanercept; HLA, human leucocyte antigen; mITT, modified } \\
\text { intent-to-treat; PBO, placebo; SIJ, sacroiliac joint; SpA, spondyloarthritis; SPARCC, } \\
\text { Spondyloarthritis Research Consortium of Canada;VAS, visual analogue scale. }\end{array}$} \\
\hline
\end{tabular}

between adalimumab and placebo for absolute changes in MRI active or structural lesions. We hypothesised that even in patients with nr-axSpA, MRI of the SIJ would be a more sensitive endpoint to demonstrate structural modification and conducted a post hoc analysis to evaluate the impact of etanercept or placebo on structural lesions at 12 weeks in patients with nr-axSpA.

\section{METHODS}

\section{Patients and study design}

EMBARK (Effect of Etanercept on Symptoms and Objective Inflammation in nr-axSpA, a 104 week study; ClinicalTrials.gov identifier: NCT01258738) ${ }^{9}$ was a randomised, controlled, phase $3 \mathrm{~b}, 104$ week clinical trial to evaluate the safety and efficacy of etanercept in patients with nr-axSpA. ${ }^{10}{ }^{11}$ Patients had axSpA per Assessment of SpondyloArthritis international Society (ASAS) criteria ${ }^{12} 13$ without meeting the $\mathrm{mNY}$ criteria for radiographic axSpA. Patients had symptoms for $>3$ months and $<5$ years, Bath Ankylosing Spondylitis Disease Activity Index (BASDAI) score $\geq 4$ and had responded inadequately to $\geq 2$ non-steroidal anti-inflammatory drugs (NSAIDs). All patients fulfilled the ASAS imaging (sacroiliitis on imaging and $\geq 1 \mathrm{SpA}$ feature) or clinical criteria (human leucocyte antigen-B27 positive and $\geq 2$ other SpA features). Patients received double-blind etanercept $50 \mathrm{mg} /$ week or placebo for 12 weeks, then open-label etanercept $50 \mathrm{mg} /$ week. $^{10}$ All patients continued background NSAIDs.

\section{Evaluation of BME of the SIJ}

In the EMBARK study, STIR scans of the SIJ and spine were assessed for BME independently by two central readers, blinded to treatment and patient characteristics, using the Spondyloarthritis Research Consortium of Canada (SPARCC) scores. ${ }^{14} 15$ The readers' mean score was used. Potential reader discrepancies were prespecified, and in these cases, an adjudicator reviewed the MRI scans and the mean of all three readers' scores was used. ${ }^{10}$ A SPARCC MRI SIJ score $\geq 2$ was considered an indicator of definite SIJ inflammation on MRI. ${ }^{16}$

\section{Evaluation of structural lesions using the SPARCC MRI SSS method}

In this analysis, the SPARCC SIJ structural score (SSS) was used to assess the structural lesions of erosion, backfill, fat metaplasia and ankylosis on T1W MRI. ${ }^{7}$ Paired baseline and 12-week T1W MRI scans were scored independently by two different readers blinded to patients, time point and inflammation scores from the STIR MRI images.

The presence or absence of lesions in SIJ quadrants (erosion, fat metaplasia) or SIJ halves (backfill, ankylosis) was recorded yes/ no using direct online data entry based on a schematic of the SIJ. Erosion and fat metaplasia were each scored from 0 to 8 per slice for five slices (total score 0-40). Backfill and ankylosis were each scored from 0 to 4 per slice for five slices (total score $0-20$ ). When assessing erosion and backfill using SSS methodology, scoring is mutually exclusive for individual quadrants on individual images. The mean of the two reader scores was used to compare change in structural lesion scores between treatment groups and to assess correlations with clinical parameters.

\section{Standardised definitions of lesions seen on T1W MRI}

The standardised definitions of SIJ structural lesions are provided below. ${ }^{671718}$ All definitions are based on T1W scans. A comparison of T1W and STIR images of erosion and backfill is provided in figure $\mathrm{S} 1$ in the online supplementary file1.

- Erosion: Full-thickness loss of the dark appearance of iliac or sacral cortical bone at its anticipated location and loss of the normal bright appearance of adjacent bone marrow.

- Backfill: Complete loss of iliac or sacral cortical bone at its anticipated location and increased signal clearly demarcated from adjacent normal marrow by dark signal with irregular contour reflecting sclerosis at the eroded bone border.

- Fat metaplasia: Increased periarticular signal on T1W sequences. Homogeneous signal across the lesion must extend $>1 \mathrm{~cm}$ in depth from the joint surface.

- Ankylosis: Bone marrow signal between the sacral and iliac bone marrow with full-thickness loss of the dark appearance of iliac and sacral cortical bone.

\section{Statistical analysis}

This analysis included the modified intent-to-treat (mITT) population with baseline and 12-week MRI scans. Treatment differences in demographic and baseline characteristics were analysed using one-way analysis of variance (ANOVA) or $\chi^{2}$ tests. Treatment differences in baseline structural lesions were analysed using one-way ANOVA. $p$ Values comparing change in lesions between etanercept and placebo were obtained from the analysis of covariance models adjusted for significant differences in patient characteristics and lesions at baseline. This analysis was repeated for the patient subsets with baseline SPARCC BME scores $\geq 2$ and $<2$. 
Two sets of cumulative probability plots were generated to compare: (1) week 12 change in erosion, backfill and fat metaplasia between etanercept and placebo-treated patients and (2) baseline scores to week 12 change from baseline per patient for erosion and backfill. The baseline and change scores were the average of the two readers.

An ordered logistic regression model tested for treatment differences among the categories of decreased or increased structural lesion scores between baseline and 12 weeks for the subgroups of SPARCC BME $\geq 2$ and $<2$ at baseline. Spearman correlations were determined between the change in each structural lesion at 12 weeks and the change in the following disease characteristics:
Ankylosing Spondylitis Disease Activity Score based on C-reactive protein (ASDAS-CRP), BASDAI, SPARCC MRI SIJ, and SPARCC MRI spine 23-discovertebral units (DVU) score. Interobserver intraclass correlation coefficients (ICC) were calculated to evaluate the level of consistency between the two MRI readers in scoring the reliability of status and 12 week change scores using the $\operatorname{ICC}(3,1)$ model.

\section{RESULTS}

\section{Patients}

Within the mITT population $(n=215), 185$ patients (etanercept, $\mathrm{n}=88$; placebo, $\mathrm{n}=97$ ) had baseline and 12-week MRI scans.

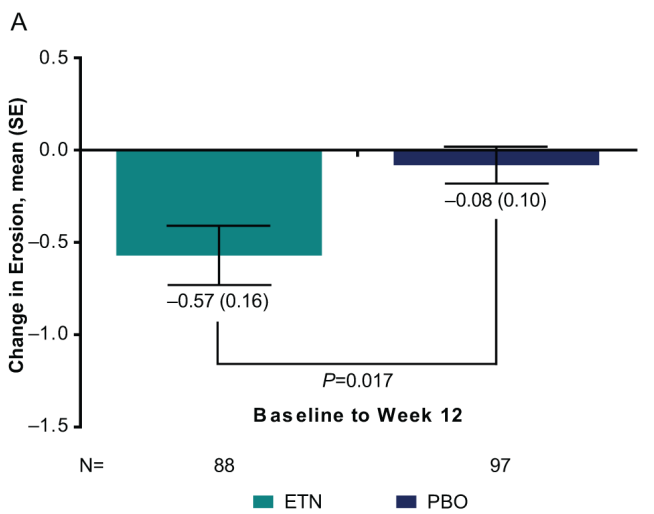

B

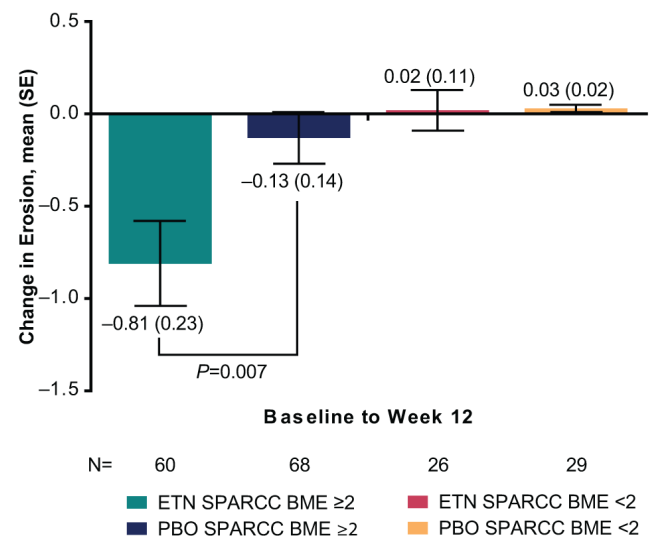

C

D
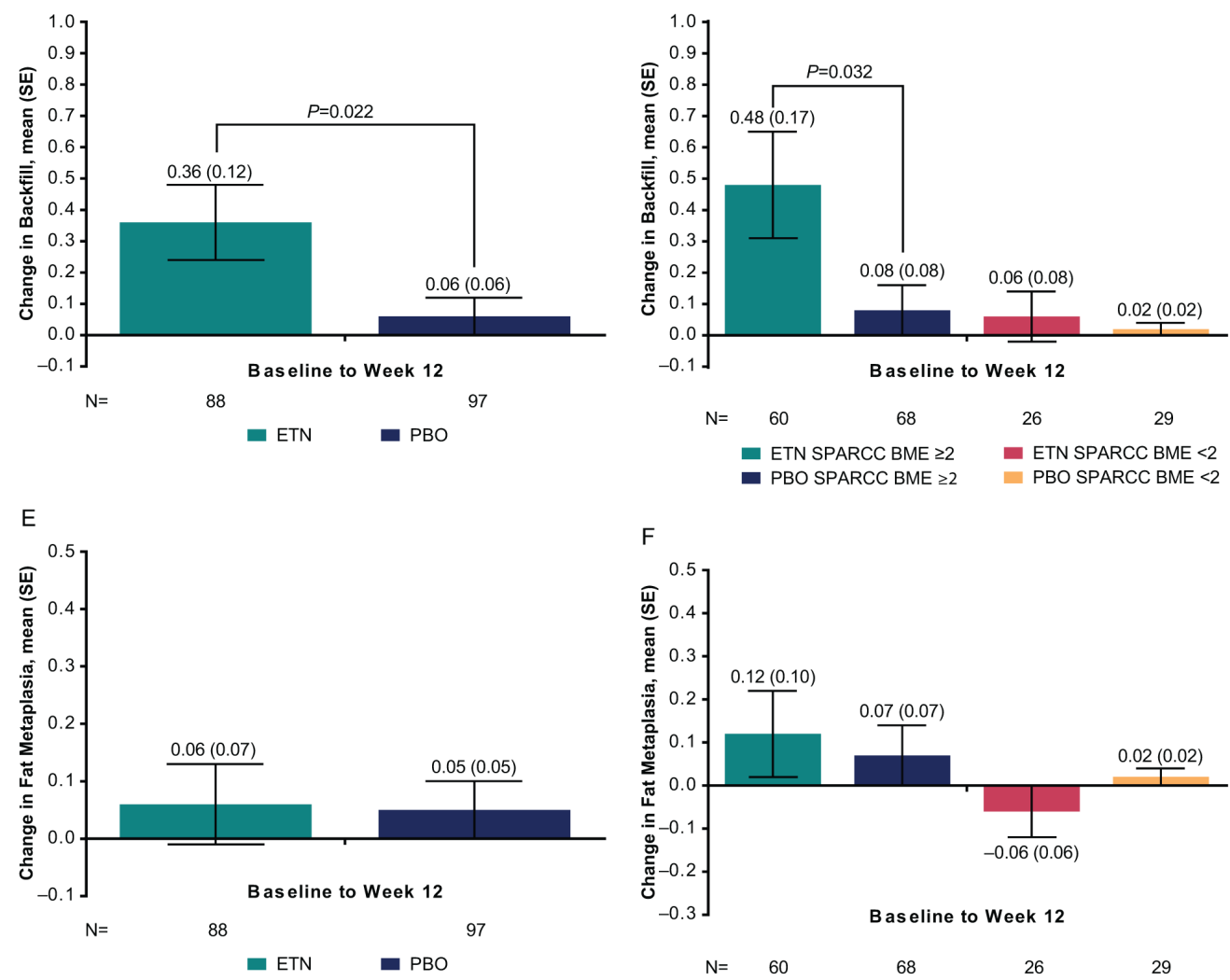

F

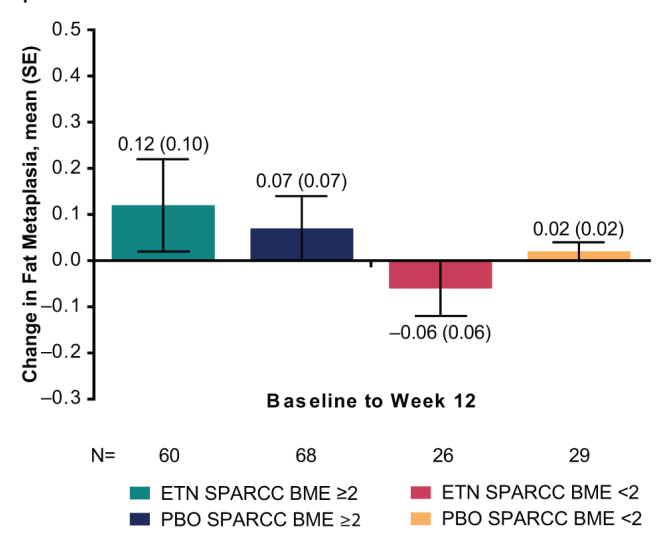

Figure 1 Mean change from baseline to week 12 with SE in (A) erosion, (B) erosion according to SPARCC BME $\geq 2$ or $<2$, (C) backfill, (D) backfill according to SPARCC BME $\geq 2$ or $<2$, (E) fat metaplasia, (F) fat metaplasia according to SPARCC BME $\geq 2$ or $<2$. $p$ Value is adjusted for lesions at baseline. Erosion and fat metaplasia range in score from 0 to 40 . Backfill ranges in score from 0 to 20. BME, bone marrow oedema; ETN, etanercept; PBO, placebo; SPARCC, Spondyloarthritis Research Consortium of Canada. 
Demographics and baseline disease characteristics were similar between the full mITT population and the population with scans (table 1). At baseline, there were no significant differences between the etanercept and placebo groups for the 185 patients in this analysis. A total of $152 / 185(82.2 \%)$ patients were ASAS MRI sacroiliitis positive and 128/183 (69.9\%) patients had MRI inflammation according to SPARCC BME score $\geq 2$.

\section{Structural lesions}

At baseline, mean (SE) SPARCC SSS for the etanercept and placebo groups, respectively, was $2.3(0.3)$ and $1.7(0.3)$ for erosion; $0.76(0.22)$ and $0.64(0.20)$ for backfill; $0.50(0.19)$ and $0.27(0.09)$ for fat metaplasia and $0.15(0.10)$ and $0.13(0.11)$ for ankylosis. The difference between treatment groups was not significant for any structural lesion.

From baseline to 12 weeks, change in mean SPARCC SSS was significantly greater for etanercept than placebo for erosion $(-0.57$ vs -0.08 , respectively; adjusted $\mathrm{p}$ value $=0.017)$ and backfill $(0.36$ vs 0.06 ; adjusted $\mathrm{p}$ value $=0.022)$ (figure 1$)$. A treatment difference was also present for the subgroup of patients with MRI inflammation at baseline, defined as a SPARCC BME score $\geq 2$; erosion: -0.81 versus -0.13 for etanercept versus placebo, respectively, $\mathrm{p}=0.007$; backfill: 0.48 versus 0.08 , $p=0.032$. Change in mean SPARCC SSS did not differ significantly between treatment groups for fat metaplasia or ankylosis at 12 weeks.

Change in erosion, backfill and fat metaplasia from baseline to week 12 is presented in cumulative probability plots (figure 2). A higher percentage of patients with change and a greater degree of reduction in erosion and increase in backfill can be noted for etanercept versus placebo; the difference in fat metaplasia is slight. Cumulative probability plots comparing baseline erosion and backfill scores to week 12 change scores per patient demonstrate that the higher the baseline erosion score, the greater the change at 12 weeks (see figure S2 in the online supplementary file 1).

Table 2 shows the proportion of patients with erosion or backfill scores that decreased, increased, or did not change between baseline and week 12 for each treatment group, according to SPARCC BME score $\geq 2$ or $<2$ at baseline. As shown, in the group with SPARCC BME $\geq 2$, there is a significant treatment difference among the change categories for erosion. In the etanercept group, erosion decreased (improved) in 15/60 (25.0\%) patients and increased (worsened) in 1/60 (1.7\%) patients, whereas in the placebo group, erosion decreased in $8 / 68(11.8 \%)$ patients and increased in $8 / 68(11.8 \%), p=0.010$. There was also a significant treatment difference among the change categories for backfill, in the group of patients with SPARCC BME $\geq 2$ : in the etanercept group, backfill increased for 8/60 (13.3\%) patients and decreased for $0 / 60(0 \%)$ and in the placebo group, backfill increased for $1 / 68(1.5 \%)$ patients and decreased for 1/68 (1.5\%, $\mathrm{p}=0.024$. The treatment differences for fat metaplasia and ankylosis were not significant.

Images comparing baseline and 12-week erosion and backfill are provided in figure 3 .

Correlations between structural lesions and clinical outcomes Spearman correlations between changes in clinical parameters and structural lesions are presented in table 3 . At 12 weeks, the decrease in erosions and increase in backfill correlated with improvement in the following responses for the etanercept group: ASDAS-CRP, BASDAI, SPARCC MRI SIJ and SPARCC spine 23-DVU (erosions only). These
A

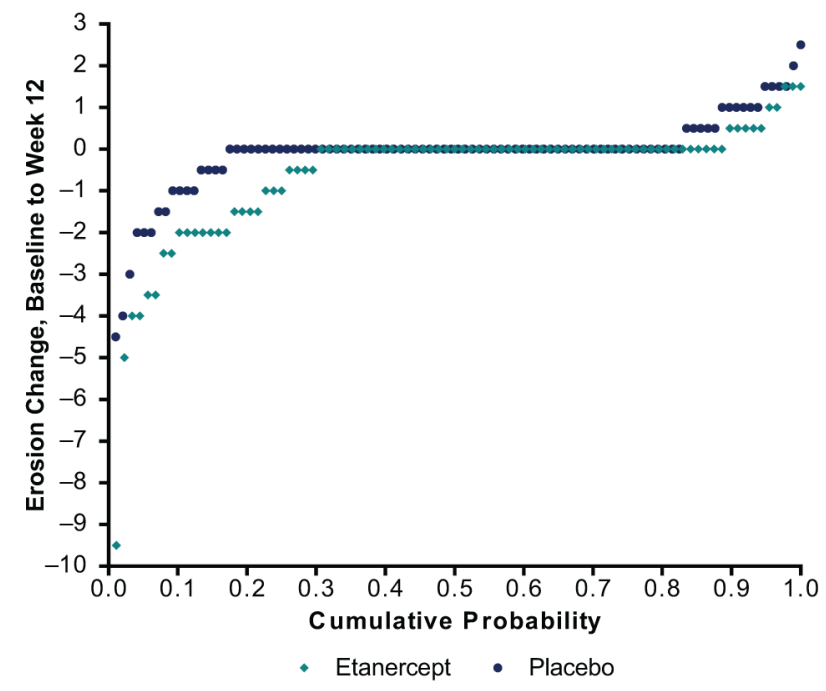

B

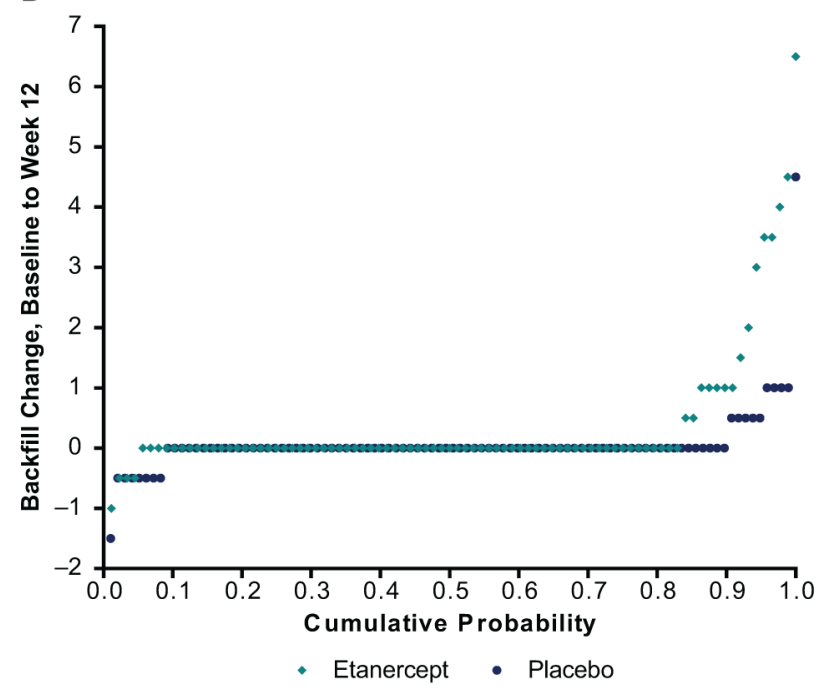

C

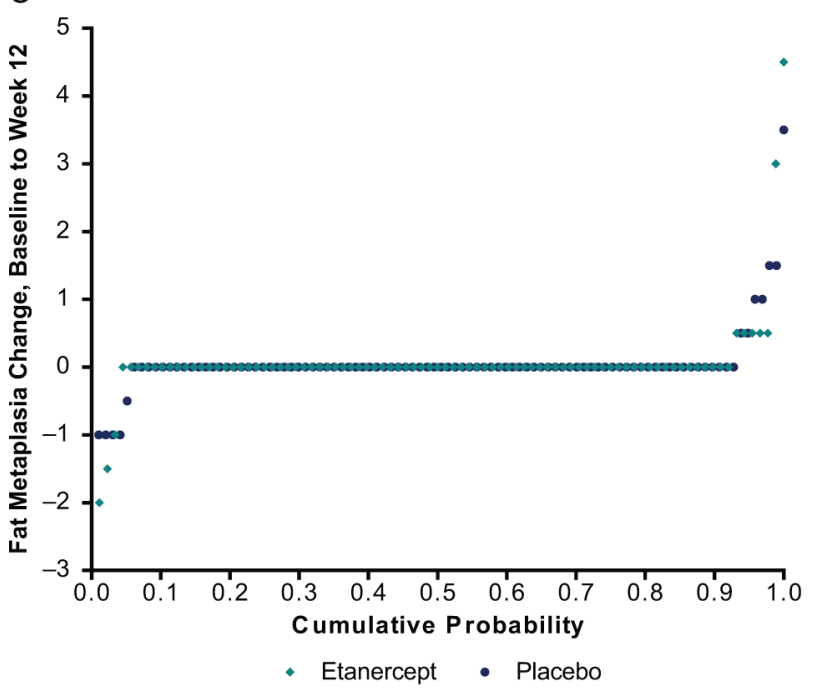

Figure 2 Cumulative probability of change from baseline to week 12 in (A) erosion, (B) backfill and (C) fat metaplasia, average of the readers. Erosion and fat metaplasia range in score from 0 to 40 . Backfill ranges in score from 0 to 20 . 
Table 2 Proportion of patients with a decrease, increase or no change in structural lesion score at week 12, according to baseline SPARCC BME

\begin{tabular}{|c|c|c|c|c|c|c|}
\hline \multirow[b]{2}{*}{ Lesion } & \multirow{2}{*}{$\begin{array}{l}\text { Baseline SPARCC } \\
\text { BME }\end{array}$} & \multirow[b]{2}{*}{ Treatment group } & \multicolumn{4}{|c|}{ Change between baseline and week $12, \mathrm{n} / \mathrm{N}(\%)$} \\
\hline & & & Decreased & Increased & No change & p Value* \\
\hline \multirow[t]{4}{*}{ Erosion } & $\geq 2$ & ETN & $15 / 60(25.0)$ & $1 / 60(1.7)$ & $44 / 60(73.3)$ & 0.010 \\
\hline & & PBO & $8 / 68(11.8)$ & $8 / 68(11.8)$ & $52 / 68(76.5)$ & \\
\hline & $<2$ & ETN & $0 / 26(0)$ & $1 / 26(3.8)$ & $25 / 26(96.2)$ & 0.958 \\
\hline & & PBO & $0 / 29(0)$ & $0 / 29(0)$ & $29 / 29(100)$ & \\
\hline \multirow[t]{4}{*}{ Backfill } & $\geq 2$ & ETN & $0 / 60(0)$ & $8 / 60(13.3)$ & $52 / 60(86.7)$ & 0.024 \\
\hline & & PBO & $1 / 68(1.5)$ & $1 / 68(1.5)$ & $66 / 68(97.1)$ & \\
\hline & $<2$ & ETN & $0 / 26(0)$ & $0 / 26(0)$ & $26 / 26(100)$ & \\
\hline & & PBO & $0 / 29(0)$ & $0 / 29(0)$ & $29 / 29(100)$ & \\
\hline
\end{tabular}

Lesion was considered to have decreased or increased if both readers categorised the change in the same direction. If one reader categorised the change as 0 , or if the readers characterised the change in opposite directions, then 'no change' was chosen.

* $p$ Value from an ordered logistic regression model which tests for a treatment difference among the change categories. BME, bone marrow oedema; ETN, etanercept; PBO, placebo; SPARCC, Spondyloarthritis Research Consortium of Canada.

correlations were weak to moderate in strength, ranging from $\mathrm{R}=0.29$ to $\mathrm{R}=0.51, \mathrm{p}<0.01$ for erosions and from $\mathrm{R}=-0.40$ to $-0.26, \mathrm{p}<0.05$ for backfill. Additionally, weak correlation was noted for the placebo group between decrease in erosions and improvement in SPARCC MRI SIJ $\operatorname{BME}(\mathrm{R}=0.25, \mathrm{p}=0.016)$.
There was little variation in the interpretations of the two MRI readers, as shown by the interobserver ICC for structural lesions (see table S1 in the online supplementary file 1). The ICC values ranged from 0.78 (backfill) to 0.98 (ankylosis) at baseline and from 0.65 (erosion) to 0.96 (ankylosis) at week 12 . For baseline to 12 week change, ICC
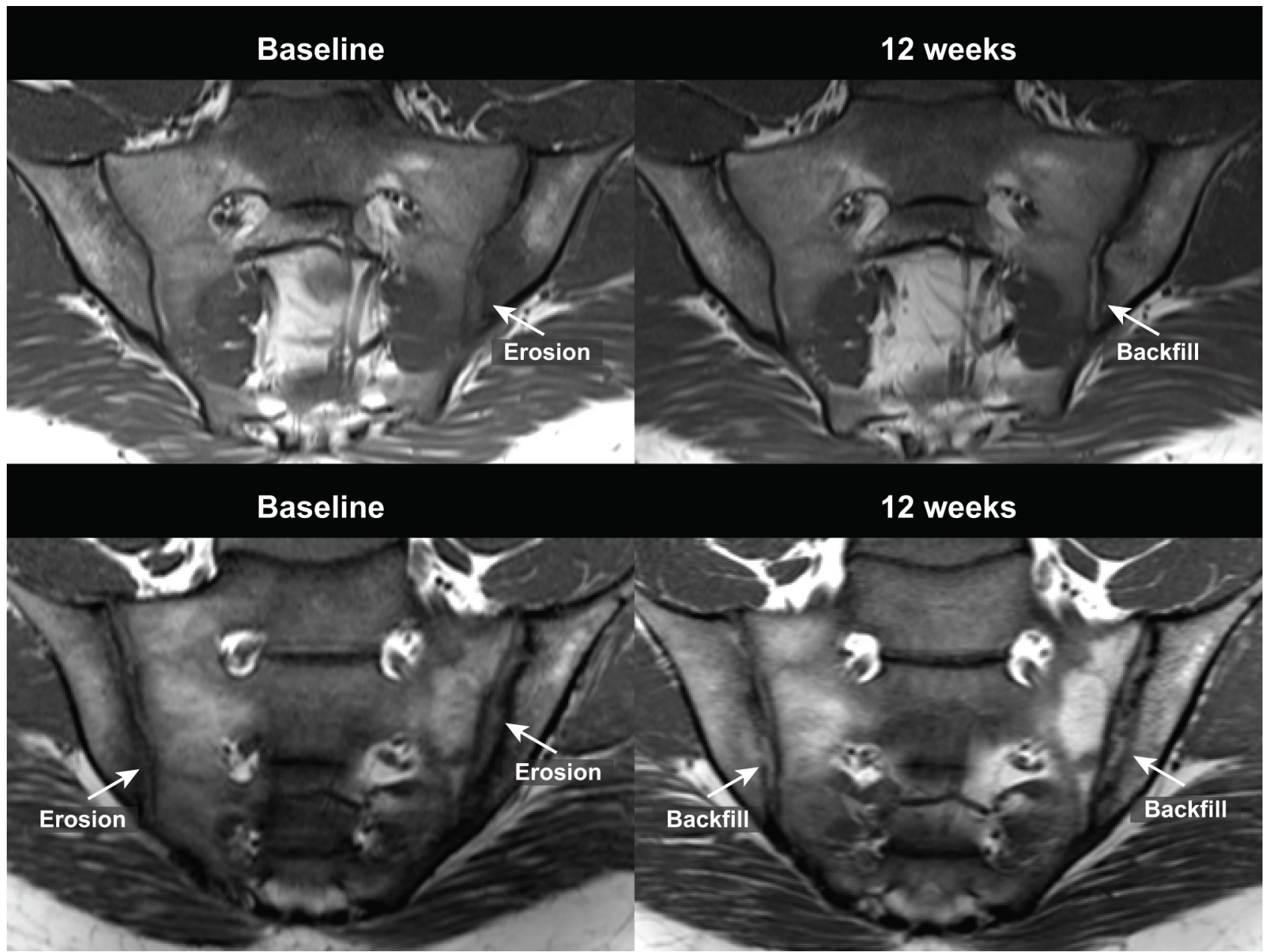

Figure 3 Example images of erosion at baseline and backfill at 12 weeks on T1 weighted MRI in two patients. On the baseline scan, erosion is indicated by loss of the dark signal of iliac cortical bone and loss of the normal bright appearance of adjacent bone marrow. On the 12-week scan, backfill is evident as characterised by increased signal at the site of erosion clearly demarcated from adjacent normal marrow by dark signal with irregular contour reflecting sclerosis at the border of the eroded bone. 
Table 3 Spearman correlations between change from baseline to week 12 in disease activity parameters and change in structural lesions

\begin{tabular}{|c|c|c|c|c|c|c|c|}
\hline & & \multicolumn{2}{|c|}{ Erosion } & \multicolumn{2}{|c|}{ Backfill } & \multicolumn{2}{|c|}{ Fat metaplasia } \\
\hline & & $\mathbf{R}$ & $p$ Value & $\mathbf{R}$ & $\mathrm{p}$ Value & $\mathbf{R}$ & $p$ Value \\
\hline \multirow[t]{2}{*}{ ASDAS-CRP } & $\begin{array}{l}\text { ETN, } \\
\mathrm{n}=83\end{array}$ & 0.40 & $<0.001$ & -0.26 & 0.018 & -0.10 & 0.352 \\
\hline & $\begin{array}{l}\mathrm{PBO}, \\
n=96\end{array}$ & -0.09 & 0.368 & 0.17 & 0.098 & 0.10 & 0.339 \\
\hline \multirow[t]{2}{*}{ BASDAI } & $\begin{array}{l}\text { ETN, } \\
\mathrm{n}=86\end{array}$ & 0.35 & $<0.001$ & -0.26 & 0.016 & -0.02 & 0.849 \\
\hline & $\begin{array}{l}\mathrm{PBO}, \\
\mathrm{n}=97\end{array}$ & -0.12 & 0.233 & 0.20 & 0.047 & 0.14 & 0.171 \\
\hline \multirow[t]{2}{*}{$\begin{array}{l}\text { SPARCC } \\
\text { MRI SIJ }\end{array}$} & $\begin{array}{l}\text { ETN, } \\
\mathrm{n}=86\end{array}$ & 0.51 & $<0.001$ & -0.40 & $<0.001$ & -0.12 & 0.269 \\
\hline & $\begin{array}{l}\mathrm{PBO}, \\
\mathrm{n}=97\end{array}$ & 0.25 & 0.016 & -0.09 & 0.379 & -0.13 & 0.219 \\
\hline \multirow{2}{*}{$\begin{array}{l}\text { SPARCC } \\
\text { spine, } \\
\text { 23-DVU }\end{array}$} & $\begin{array}{l}\text { ETN, } \\
n=86\end{array}$ & 0.29 & 0.007 & -0.20 & 0.072 & -0.08 & 0.442 \\
\hline & $\begin{array}{l}\mathrm{PBO}, \\
\mathrm{n}=97\end{array}$ & -0.04 & 0.674 & -0.04 & 0.735 & -0.11 & 0.299 \\
\hline \multicolumn{8}{|c|}{$\begin{array}{l}\text { ASDAS-CRP, Ankylosing Spondylitis Disease Activity Score calculated using } \\
\text { C-reactive protein; BASDAI, Bath Ankylosing Spondylitis Disease Activity Index; } \\
\text { BME, bone marrow oedema; DVU, discovertebral unit; ETN, etanercept; PBO, } \\
\text { placebo; R, Spearman correlation; SPARCC, Spondyloarthritis Research Consortium } \\
\text { of Canada. }\end{array}$} \\
\hline
\end{tabular}

values were $0.62,0.76$ and 0.78 for erosion, backfill and fat metaplasia, respectively.

\section{DISCUSSION}

In this post hoc analysis, we show for the first time in a placebo-controlled RCT in axSpA that etanercept treatment is associated with structure-modifying effects using MRI structural lesions in the SIJ as the primary outcome. We observed significantly greater reduction in erosion and increase in backfill at 12 weeks for etanercept compared with placebo, consistent with a very early reparative response. This was primarily apparent in patients with baseline inflammation on MRI. These results add to the findings from a small trial of patients, most with ankylosing spondylitis, which demonstrated change from baseline in BME and structural lesions on MRI following 12 weeks of adalimumab therapy. ${ }^{8}$

Previously, we demonstrated in a 2-year observational cohort that anti-TNF therapy was associated with significant reduction in erosion. ${ }^{19}$ Now we show that this treatment effect can be observed by 12 weeks. A previous comparison of etanercept versus sulfasalazine in patients with early SpA and substantially more baseline radiographic disease than in EMBARK demonstrated no treatment differences in erosion scores at 24 weeks. ${ }^{20}$ That study used whole body MRI and quantified erosion in the SIJ using a grading scheme based on the number of erosions per SIJ $(1=1-2 ; 2=3-5 ; 3=>5$ erosions per SIJ). This scoring method is limited because erosion may affect the entire vertical height of the iliac or sacral bone on a coronal scan, thus, these cannot be considered discrete lesions. Additionally, it is difficult to assess whether the size of an erosion decreased substantially without affecting the number of erosions. Alternative MRI sequences, such as opposed-phase gradient-echo sequences, may permit more reliable and sensitive assessment for detecting erosions in clinical trials in the future.

An important observation from this study is that in patients treated with an anti-TNF, resolution of erosion is associated with the development of new tissue at the erosion cavity that appears bright on T1W MRI. This observation together with an irregular dark band is termed backfill because it potentially reflects the in-filling of an eroded cavity bordered by sclerotic bone. An association between resolution of erosion and the appearance of backfill was previously reported in a 2 -year observational cohort. ${ }^{19}$ This reparative tissue resembles in its signal intensity characteristics of the fat metaplasia observed on T1W MRI in subchondral bone marrow after resolution of inflammation. Data from this RCT indicate that the earliest reparative response after anti-TNF therapy is the appearance of backfill, because we did not observe any impact of treatment on the development of fat metaplasia at 12 weeks, despite resolution of SIJ bone marrow inflammation. ${ }^{10}$ Fat metaplasia was evident by 48 weeks, and it correlated with resolution of SIJ bone marrow inflammation. ${ }^{11}$ Previous comparison of etanercept versus sulfasalazine showed that anti-TNF therapy was associated with development of fat metaplasia after 24 weeks and this was directly associated with resolution of inflammation. ${ }^{20}$ The lack of change in fat metaplasia in EMBARK at 12 weeks may be due to a shorter treatment duration at the follow-up MRI assessment.

The correlations between MRI and clinical parameters reported here and in a previous EMBARK publication ${ }^{11}$ are stronger than in previously published SpA clinical studies. ${ }^{21} 22$ This may reflect the short symptom duration of patients in this trial and/or the substantial differences in lesion scoring methodology used in EMBARK. These correlation data support the validity of the MRI feature of backfill as a reparative lesion, because the correlations are negative with several parameters reflecting disease activity that are scored independently from structural lesions: ASDAS, BASDAI and SPARCC MRI SIJ.

The primary study limitation is that the prognostic implications for development of new bone with these structural lesion changes are unclear. Several reports have described associations between vertebral corner fat metaplasia on T1W MRI and development of new syndesmophytes on radiographic follow-up. ${ }^{2023-25}$ We reported that fat metaplasia in the SIJ is also an intermediary tissue between inflammation and ankylosis development in the SIJ. ${ }^{6}$ MRI data from studies of both SIJ and spine suggest that the disease evolves over at least two stages, irrespective of treatment. First, resolution of inflammation may be followed by fat metaplasia in bone marrow and backfill at the erosion site. However, reduction in the extent of erosion may be observed without development of backfill. Second, ongoing tissue remodelling in regions of fat metaplasia and backfill may be followed by development of new bone. Anti-TNF therapy clearly accelerates the first stage, but its impact on the second stage is unclear.

The impact of anti-TNF therapy should be explored in larger and longer studies with radiographic endpoints assessing new bone. However, even if anti-TNF therapy does not impact this second stage of lesion evolution, identification of patients with a propensity to develop fat metaplasia early in the disease course could help select patients for early treatment intervention. A preliminary report from an observational cohort shows that SIJ fat metaplasia independently predicts new bone formation in the spine. ${ }^{26}$

Improvement in several clinical measures correlated with decreases in erosion and increases in backfill in patients receiving etanercept. This may reflect the substantial improvement in SIJ BME over the 12 weeks between MRI assessments. In the 48-week analysis, we reported substantial correlation between improved clinical measures of disease activity and reduction in SIJ BME. ${ }^{11}$ Also, correlations between clinical improvement and resolution of SIJ erosion for patients receiving etanercept 
were slightly greater than correlations between improvement in spinal inflammation and resolution of SIJ erosion. Relatively few patients had spinal inflammation since patients with symptom duration $>5$ years were excluded. Consequently, it is likely that clinical measures more closely reflect sacroiliac rather than spinal lesions on imaging. Further analysis in larger datasets is necessary to determine whether changes in these structural lesions or the accompanying decrease in inflammation were independently responsible for clinical improvement.

In conclusion, using the SPARCC SSS method, a validated semiquantitative MRI-based scoring method for assessing structural lesions in the SIJ, we demonstrated in an RCT that etanercept treatment results in amelioration of erosions as early as 12 weeks in patients with nr-axSpA. This was accompanied by a reparative tissue response at the site of erosion that correlated with clinical improvement. Understanding the effect of etanercept treatment on new bone formation and maintenance of clinical response beyond 2 years in this population with early disease requires further study using radiographic endpoints in long-term prospective cohorts.

Acknowledgements We wish to thank all the patients who participated in this study, as well as the investigators and medical staff at all of the participating centres.

Contributors Study conception or design:WPM, MD, HJ, RP, AS, JFB, RGL. Acquisition of data: WPM, MD, SW, JFB and RGL. All authors were involved in the drafting of the article, analysis or interpretation of data or revising it critically for important intellectual content. All authors approved the final version to be published. All authors agreed to be accountable for all aspects of the work.

Funding This study was funded by Pfizer. Medical writing support was provided by Jennica Lewis, PharmD, CMPP of Engage Scientific Solutions and was funded by Pfizer.

Competing interests WPM has received consulting fees from AbbVie, Amgen, Lilly, Janssen, Pfizer, Sanofi and UCB and is the chief medical officer of CaRE Arthritis Ltd. MD is a consultant for and has received research funding/grants from AbbVie, Lilly, Merck, Pfizer, Sanofi and UCB. HJ, RP, LM and JFB are employees of and own stock in Pfizer. AS is an employee of inVentiv Health and was contracted by Pfizer to provide statistical support for the development of this paper. SW and RGL have no competing interests to declare.

Ethics approval Each study center obtained approval by a duly constituted Institutional Review Board or Independent Ethics Committee.

Provenance and peer review Not commissioned; externally peer reviewed.

Open Access This is an Open Access article distributed in accordance with the Creative Commons Attribution Non Commercial (CC BY-NC 4.0) license, which permits others to distribute, remix, adapt, build upon this work non-commercially, and license their derivative works on different terms, provided the original work is properly cited and the use is non-commercial. See: http://creativecommons.org/ licenses/by-nc/4.0/

(c) Article author(s) (or their employer(s) unless otherwise stated in the text of the article) 2018. All rights reserved. No commercial use is permitted unless otherwise expressly granted.

\section{REFERENCES}

1 Heuft-Dorenbosch L, Landewé R, Weijers R, et al. Combining information obtained from magnetic resonance imaging and conventional radiographs to detect sacroiliitis in patients with recent onset inflammatory back pain. Ann Rheum Dis 2006;65:804-8.

2 Oostveen J, Prevo R, den Boer J, et al. Early detection of sacroiliitis on magnetic resonance imaging and subsequent development of sacroiliitis on plain radiography. A prospective, longitudinal study. J Rheumatol 1999;26:1953-8.

3 Bennett AN, McGonagle D, O'Connor $\mathrm{P}$, et al. Severity of baseline magnetic resonance imaging - evident sacroiliitis and HLA-B27 status in early inflammatory back pain predict radiographically evident ankylosing spondylitis at eight years. Arthritis Rheum 2008:58:3413-8.

4 van der Heijde D, Sieper J, Maksymowych WP, et al. Spinal inflammation in the absence of sacroiliac joint inflammation on magnetic resonance imaging in patients with active nonradiographic axial spondyloarthritis. Arthritis Rheumatol 2014:66:667-73.

5 Weber U, Lambert RG, Pedersen SJ, et al. Assessment of structural lesions in sacroiliac joints enhances diagnostic utility of magnetic resonance imaging in early spondylarthritis. Arthritis Care Res 2010;62:1763-71.
6 Maksymowych WP, Wichuk S, Chiowchanwisawakit P, et al. Fat metaplasia and backfill are key intermediaries in the development of sacroiliac joint ankylosis in patients with ankylosing spondylitis. Arthritis Rheumatol 2014;66:2958-67.

7 Maksymowych WP, Wichuk S, Chiowchanwisawakit P, et al. Development and preliminary validation of the spondyloarthritis research consortium of Canada magnetic resonance imaging sacroiliac joint structural score. J Rheumatol 2015;42:79-86.

8 Pedersen SJ, Poddubnyy D, Sørensen IJ, et al. Course of magnetic resonance imaging - detected inflammation and structural lesions in the sacroiliac joints of patients in the randomized, double-blind, placebo-controlled Danish multicenter study of adalimumab in spondyloarthritis, as assessed by the Berlin and spondyloarthritis research consortium of Canada methods. Arthritis Rheumatol 2016:68:418-29.

9 Dougados M, van der Heijde D, Sieper J, et al. Effects of long-term etanercept treatment on clinical outcomes and objective signs of inflammation in early nonradiographic axial spondyloarthritis: 104-week results from a randomized, placebo-controlled study. Arthritis Care Res 2017.

10 Dougados M, van der Heijde D, Sieper J, et al. Symptomatic efficacy of etanercept and its effects on objective signs of inflammation in early nonradiographic axial spondyloarthritis: a multicenter, randomized, double-blind, placebo-controlled trial. Arthritis Rheumatol 2014;66:2091-102.

11 Maksymowych WP, Dougados M, van der Heijde D, et al. Clinical and MRI responses to etanercept in early non-radiographic axial spondyloarthritis: 48-week results from the EMBARK study. Ann Rheum Dis 2016;75:1328-35.

12 Rudwaleit M, Jurik AG, Hermann KG, et al. Defining active sacroilitis on magnetic resonance imaging (MRI) for classification of axial spondyloarthritis: a consensual approach by the ASAS/OMERACT MRI group. Ann Rheum Dis 2009;68:1520-7.

13 Sieper J, Rudwaleit M, Baraliakos X, et al. The assessment of spondyloArthritis international Society (ASAS) handbook: a guide to assess spondyloarthritis. Ann Rheum Dis 2009;68(Suppl 2):ii1-ii44.

14 Maksymowych WP, Inman RD, Salonen D, et al. Spondyloarthritis research consortium of Canada magnetic resonance imaging index for assessment of spinal inflammation in ankylosing spondylitis. Arthritis Rheum 2005:53:502-9.

15 Maksymowych WP, Inman RD, Salonen D, et al. Spondyloarthritis research Consortium of Canada magnetic resonance imaging index for assessment of sacroiliac joint inflammation in ankylosing spondylitis. Arthritis Rheum 2005:53:703-9.

16 van den Berg R, de Hooge M, Bakker PA, et al. Metric properties of the SPARCC score of the Sacroiliac Joints - data from baseline, 3-month, and 12-month followup in the SPACE cohort. J Rheumatol 2015;42:1186-93.

17 Weber U, Pedersen SJ, Østergaard M, et al. Can erosions on MRI of the sacroiliac joints be reliably detected in patients with ankylosing spondylitis? A cross-sectional study. Arthritis Res Ther 2012;14:R124.

18 Østergaard M, Maksymowych WP, Pedersen SJ, et al. Structural lesions detected by magnetic resonance imaging in the spine of patients with spondyloarthritis - definitions, assessment system, and reference image set. J Rheumatol 2009:84:18-34.

19 Pedersen SJ, Wichuk S, Chiowchanwisawakit P, et al. Tumor necrosis factor inhibitor therapy but not standard therapy is associated with resolution of erosion in the sacroiliac joints of patients with axial spondyloarthritis. Arthritis Res Ther 2014; $16: R 100$

20 Song IH, Hermann KG, Haibel $\mathrm{H}$, et al. Relationship between active inflammatory lesions in the spine and sacroiliac joints and new development of chronic lesions on whole-body MRI in early axial spondyloarthritis: results of the ESTHER trial at week 48. Ann Rheum Dis 2011;70:1257-63.

21 Machado P, Landewé RB, Braun J, et al. MRI inflammation and its relation with measures of clinical disease activity and different treatment responses in patients with ankylosing spondylitis treated with a tumour necrosis factor inhibitor. Ann Rheum Dis 2012;71:2002-5.

22 Weiß A, Song IH, Haibel H, et al. Good correlation between changes in objective and subjective signs of inflammation in patients with short- but not long duration of axial spondyloarthritis treated with tumor necrosis factor-blockers. Arthritis Res Ther 2014;16:R35.

23 Baraliakos X, Heldmann F, Callhoff J, et al. Which spinal lesions are associated with new bone formation in patients with ankylosing spondylitis treated with anti-TNF agents? A long-term observational study using MRI and conventional radiography. Ann Rheum Dis 2014;73:1819-25.

24 Machado PM, Baraliakos X, van der Heijde D, et al. MRI vertebral corner inflammation followed by fat deposition is the strongest contributor to the development of new bone at the same vertebral corner: a multilevel longitudinal analysis in patients with ankylosing spondylitis. Ann Rheum Dis 2016;75:1486-93.

25 Chiowchanwisawakit P, Lambert RG, Conner-Spady B, et al. Focal fat lesions at vertebral corners on magnetic resonance imaging predict the development of new syndesmophytes in ankylosing spondylitis. Arthritis Rheum 2011;63:2215-25.

26 Maksymowych W, Wichuk S, Chiowchanwisawakit P, et al. Fat metaplasia on MRI of the sacroiliac joints is a lead indicator of radiographic progression in the spine of patients with ankylosing spondylitis (abstract). Arthritis Rheumatol 2014;66:S1305. 